\title{
Short Circuits of a 10-MW High-Temperature Superconducting Wind Turbine Generator
}

Song, Xiaowei (Andy); Liu, Dong; Polinder, Henk; Mijatovic, Nenad; Holbøll, Joachim; Jensen, Bogi Bech

Published in:

IEEE Transactions on Applied Superconductivity

Link to article, DOI:

10.1109/TASC.2017.2656623

Publication date:

2017

Document Version

Peer reviewed version

Link back to DTU Orbit

Citation (APA):

Song, X., Liu, D., Polinder, H., Mijatovic, N., Holbøll, J., \& Jensen, B. B. (2017). Short Circuits of a 10-MW HighTemperature Superconducting Wind Turbine Generator. IEEE Transactions on Applied Superconductivity, 27(4), [5201505]. https://doi.org/10.1109/TASC.2017.2656623

\section{General rights}

Copyright and moral rights for the publications made accessible in the public portal are retained by the authors and/or other copyright owners and it is a condition of accessing publications that users recognise and abide by the legal requirements associated with these rights.

- Users may download and print one copy of any publication from the public portal for the purpose of private study or research.

- You may not further distribute the material or use it for any profit-making activity or commercial gain

- You may freely distribute the URL identifying the publication in the public portal 


\title{
Short Circuits of a 10 MW High Temperature Superconducting Wind Turbine Generator
}

\author{
Xiaowei Song, Dong Liu, Henk Polinder, Senior Member, IEEE, Nenad Mijatovic, Member, IEEE, \\ Joachim Holbøll, Senior Member, IEEE, and Bogi Bech Jensen, Senior Member, IEEE
}

\begin{abstract}
Direct drive high temperature superconducting (HTS) wind turbine generators have been proposed to tackle challenges for ever increasing wind turbine ratings. Due to smaller reactances in HTS generators, higher fault currents and larger transient torques could occur if sudden short circuits happen at generator terminals. In this paper, a finite element model that couples magnetic fields and the generator's equivalent circuits is developed to simulate short circuit faults. Afterwards, the model is used to study the transient performance of a $10 \mathrm{MW}$ HTS wind turbine generator under four different short circuits, i.e., three-phase, phase-phase clear of earth, phase-phase-earth, and phase-earth. The stator current, fault torque, and field current under each short circuit scenario are examined. Also included are the forces experienced by the HTS field winding under short circuits. The results show that the short circuits pose great challenges to the generator, and careful consideration should be given to protect the generator. The findings presented in this paper would be beneficial to the design, operation and protection of an HTS wind turbine generator.
\end{abstract}

Index Terms-Finite element analysis, force, high temperature superconducting generator, short circuit, transient.

\section{INTRODUCTION}

$\mathbf{H}$ IGH temperature superconducting (HTS) generators have higher torque densities compared to their conventional counterparts. Therefore, HTS generators are expected to provide a competitive drive train for wind turbines with large power ratings [1]. Studies of HTS wind turbine generators in $10 \mathrm{MW}$ rating and above have been of great interest, and several designs have been proposed [2]-[4].

Given the high price of HTS tapes commercially available in the market, a cost-effective design option is to employ a salient-pole iron rotor and an iron-toothed stator [5]. This topology results in a partially superconducting machine, i.e., a copper AC armature winding and an HTS DC field winding, in which a large magnetic air gap exists because of needed space for a cryostat wall and the thermal insulations [6]. Consequently, the reactance is lower than that in a conventional machine [7]. A lower reactance, on one hand, provides a faster dynamic response and a higher load capacity, and on the other hand, leads to a higher fault current and a larger transient torque under short circuit conditions [8], [9]. For instance, a peak value of the fault torque could be as high as ten times

X. Song, N. Mijatovic, and J. Holbøll are with the Center for Electric Power and Energy, Department of Electrical Engineering, Technical University of Denmark (DTU), 2800 Lyngby, Denmark (e-mail: song@elektro.dtu.dk).

D. Liu and H. Polinder are with the Department of Electrical Sustainable Energy, Delft University of Technology, 2628 Delft, the Netherlands.

B. B. Jensen is with the Department of Science and Technology, University of the Faroe Islands, 100 Torshavn, Faroe Islands. the rated value. It would be very challenging to design the mechanical structure of a generator to withstand such a high peak torque since usually the generator structure is designed for three times the rated torque [10].

Unlike conventional generators in which the interests under short circuit conditions are mainly focused on stator currents and fault torques, in superconducting generators field currents are also of vital importance since they may exceed critical values and permanent damage to superconducting windings is possible [7]. Besides, large forces experienced by superconducting windings during short circuits cause excessive stresses and strains, which influence critical currents adversely.

Superconducting generators' performance under short circuit conditions has been studied in several publications. An analytical model and a finite element (FE) model were introduced in [8] and [11], respectively, to simulate short circuits in HTS machines. [12] reported influences of a series of generator parameters on stator currents and fault torques, assuming a constant rotating speed. [13] dealt with effects of electromagnetic (EM) shields and different armature teeth on stator currents and torques as well as field currents. Both [12] and [13] considered a three-phase short circuit under no load condition. The performance of HTS field windings under fault conditions was presented in [14] and [15], either focusing on over-current capabilities and thermal transient responses, or on magnetic fields.

Nevertheless, further improvements can be made. For example, it makes more sense to consider mechanical dynamics than assuming a constant rotating speed. Assuming a constant rotating speed means the drive torque always equals to the electromagnetic torque, which is unrealistic since the latter changes significantly during short circuits. In addition, different short circuits have different consequences, therefore, a systematic study of different short circuits is necessary to find the worst-case scenarios.

In this paper, a model that couples magnetic fields and the generator's equivalent circuits is developed to study the transient performance of a 10 MW HTS wind turbine generator. By using the model, four different short circuit scenarios, i.e., three-phase, phase-phase clear of earth, phasephase-earth, and phase-earth, are systematically studied. The stator current, fault torque, and field current under each short circuit scenario are investigated, and the forces experienced by the field winding under short circuits are also examined. By comparing different consequences, the objective of the paper is to determine the worst-case scenarios, which could provide valuable inputs for the design of HTS generators. 


\section{TYPES AND MODELLING OF SHORT CIRCUITS}

\section{A. Types of Short Circuits}

Four different short circuit faults (SCF) could happen at generator terminals, i.e., three-phase (L-L-L), phase-phase clear of earth (L-L), phase-phase-earth (L-L-Earth), and phaseearth (L-Earth), as illustrated in Fig. 1 [16]. Note that normally the neutral line of a generator is not grounded. In L-L-Earth and L-Earth short circuits, the worst case is that the neutral line is accidentally grounded, as depicted by the dashed lines in Fig. 1 (c) and (d). Although the occurrence is rare, the fault currents are so large that they could exceed a three-phase fault current. Therefore, in this paper the neutral line is deliberately grounded when studying L-L-Earth and L-Earth short circuits.

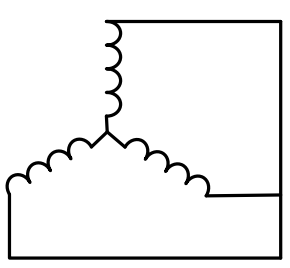

(a) L-L-L SCF

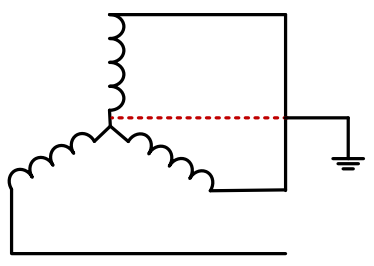

(c) L-L-Earth SCF

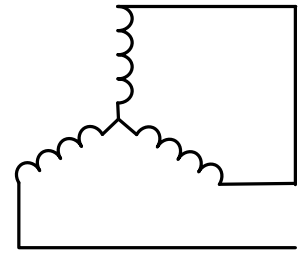

(b) L-L SCF

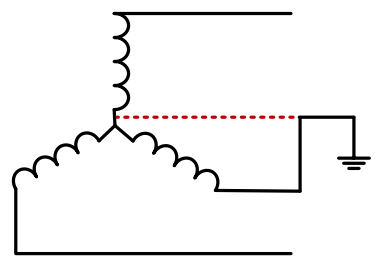

(d) L-Earth SCF
Fig. 1. Types of short circuit faults at generator terminals.

\section{B. Modelling of Short Circuits}

A two dimensional (2-D) model which couples the computation of magnetic fields and the generator's equivalent circuits is developed to simulate short circuit faults in a superconducting generator.

The flux linkages in three phases $\lambda_{a}, \lambda_{b}, \lambda_{c}$, and their time differentials $\frac{d \lambda_{a}}{d t}, \frac{d \lambda_{b}}{d t}, \frac{d \lambda_{c}}{d t}$ are computed in a finite element (FE) model, and then coupled with the generator's equivalent circuits to get three phase currents $i_{a}, i_{b}$, and $i_{c}$. The flux linkage in the field winding $\lambda_{f}$ and its time differential $\frac{d \lambda_{f}}{d t}$, as well as the field current $i_{f}$, can be solved in the same way.

The generator's equivalent circuits are given by [8] [13]:

$$
\begin{aligned}
& u_{a}=\frac{d \lambda_{a}}{d t}-r_{s} i_{a}-L_{\sigma s} \frac{d i_{a}}{d t} \\
& u_{b}=\frac{d \lambda_{b}}{d t}-r_{s} i_{b}-L_{\sigma s} \frac{d i_{b}}{d t} \\
& u_{c}=\frac{d \lambda_{c}}{d t}-r_{s} i_{c}-L_{\sigma s} \frac{d i_{c}}{d t} \\
& u_{f}=\frac{d \lambda_{f}}{d t}+r_{f} i_{f}+L_{\sigma f} \frac{d i_{f}}{d t}
\end{aligned}
$$

where $u_{a}, u_{b}$, and $u_{c}$ are the phase winding terminal voltages; $u_{f}$ is the field winding terminal voltage; $r_{s}$ and $r_{f}$ are the resistances for the phase winding and field winding, respectively. The end winding leakage inductances $L_{\sigma s}$ and $L_{\sigma f}$ for the phase winding and field winding are also included. It is necessary to point out that it is more practical to excite the field winding by a voltage source rather than a current source. The reason is that an unrealistic over voltage and instantaneous power should be provided by the current source if a short circuit happens [13].

By assigning proper constraints to $u_{a}, u_{b}$, and $u_{c}$, different short circuits can be achieved. For example, $u_{a}=0$ realizes an L-Earth short circuit, while $u_{a}=u_{b}$ realizes an L-L short circuit.

The mechanical dynamics can be integrated into the model by:

$$
T_{m}-T_{e}=J \frac{d \omega_{m}}{d t}
$$

where $T_{m}$ is the mechanical torque that drives the generator; $T_{e}$ is the electromagnetic torque produced by the generator; $J$ is the moment of inertia of the whole drive train, including the blades, hub, shaft and generator itself; $\omega_{m}$ is the mechanical rotating speed of the rotor. Under no load conditions, $T_{m}$ equals zero; under rated load conditions, $T_{m}$ equals the rated electromagnetic torque of the generator.

The model described above is implemented both in Ansoft Maxwell and Comsol to study L-L-L and L-L short circuits of a $10 \mathrm{MW}$ low temperature superconducting (LTS) wind turbine generator proposed by General Electric (GE) Global Research. The results obtained from Ansoft Maxwell and Comsol are in good agreement with each other, and also with those in [10].

\section{ShORT CIRCUITS OF A $10 \mathrm{MW}$ HTS WIND TURBINE GENERATOR}

\section{A. Generator Model}
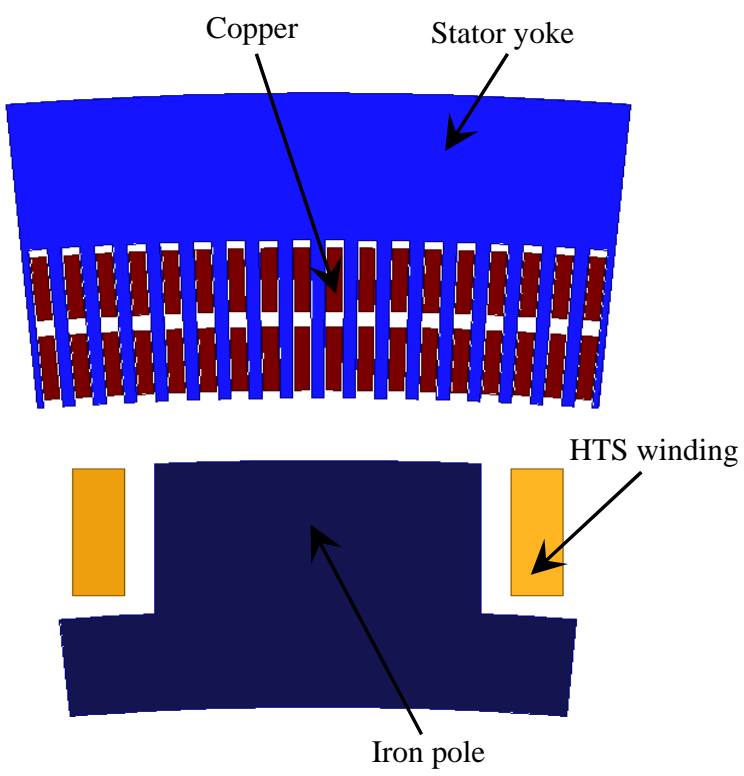

Fig. 2. Illustration of a one-pole segment of the modified 10 MW HTS wind turbine generator. 
TABLE I

SPECIFICATIONS OF THE HTS FIELD WINDING

\begin{tabular}{lc}
\hline \hline Width of the HTS tape $(\mathrm{mm})$ & 12 \\
Thickness of the HTS tape $(\mathrm{mm})$ & 0.2 \\
No. of layers per coil & 8 \\
No. of tapes per layer & 110 \\
Operating temperature (K) & 30 \\
Operating current (A) & 388 \\
Critical current (A) & 550 \\
\hline \hline
\end{tabular}

A 10 MW direct drive LTS wind turbine generator introduced in [10] has been modified to an HTS generator. A onepole segment of the HTS generator is illustrated in Fig. 2. By replacing the LTS field winding with the HTS field winding, the specifications of the field winding change accordingly, as listed in Table I.

The HTS generator has the same output power and stator specifications as the original LTS generator, except the changes in the air gap, EM shield, and rotor. The magnetic air gap of the generator is decreased from $84 \mathrm{~mm}$ to $50 \mathrm{~mm}$ since the HTS field winding has a less demanding requirement of thermal insulation than the LTS field winding does. The EM shield is eliminated in the HTS generator as it has very limited influence on short circuits [13]. Also, an iron pole is adopted in the rotor to reduce the usage of HTS tapes.

Compared to conventional generators, the HTS generator studied here has a much larger air gap, and also the iron components of the HTS generator are saturated. These two factors give rise to a smaller reactance, which differentiates the HTS generator here from conventional ones in terms of short circuit performance.

\section{B. Stator Currents and Faults Torques}

The generator operates at the rated condition from 0 to $1 \mathrm{~s}$. The short circuits then take place at the instant of $1 \mathrm{~s}$ when the voltage in phase A is passing through zero and the flux linkage in phase A is maximum. Therefore, maximum fault currents occur in phase A. Fig. 3 and Fig. 4 respectively show the current waveforms in phase $\mathrm{A}$ and the torque waveforms of the generator five seconds after the instant of short circuits.

As shown in Fig. 3, the stator currents increase to their peak values within the first half circle after the instant of short circuits. The maximum peak value of the stator currents is 18 times the rated value, and occurs in an L-L-Earth short circuit. Fig. 4 indicates that the generator produces a maximum torque of 10 times the rated value when an L-L short circuit happens at the generator terminals. Such high stator currents and fault torques pose a great challenge to the generator. For example, the insulation of the stator winding may get burnt due to intense heating during short circuits, or the generator mechanical component could collapse if, for instance, protective devices fail to clear short circuits fast enough.

\section{Field Currents}

Similar to the stator currents, the field currents also increase after the instant of short circuits. This phenomenon can be
TABLE II

FORCES ON THE HTS FIELD WINDING DURING SHORT CIRCUITS

\begin{tabular}{lcc}
\hline \hline Types of short circuits & $\begin{array}{c}\text { Peak values of } \\
F_{\tau} \text { (Per unit) }\end{array}$ & $\begin{array}{c}\text { Peak values of } \\
F_{r} \text { (Per unit) }\end{array}$ \\
L-L-L & 9.47 & 4.6 \\
L-L & 10.7 & 4.4 \\
L-L-Earth & 10.4 & 4.5 \\
L-Earth & 9.7 & 3.8 \\
\hline \hline
\end{tabular}

understood by the fact that the flux linkage in any winding can not change instantaneously. Short circuits tend to decrease the flux linkage, thus both the stator currents and the field currents increase to maintain the flux linkage.

Fig. 5 depicts the variations of the field currents in 2 seconds after the instant of four different types of short circuits. It can be seen that the field currents have peak values about $40 \%$ higher than the rated ones in L-L-L, L-L, and L-LEarth short circuits, and about $30 \%$ higher in an L-Earth short circuit. The increase of the field currents leads to elevated magnetic fields experienced by the HTS tapes, and the critical currents decrease consequently. The reason is that the critical current decreases when the magnetic field increases, especially the component perpendicular to the wide face of the HTS tape. Referring to the field dependency of $I_{c}$ provided by the HTS tape manufacturer, the variations of critical currents with respect to time can be obtained, as plotted by the dotted lines in Fig. 5. Note that the critical currents in Fig. 5 is obtained based on an assumption that the cryogenic system is able to provide sufficient cooling power to maintain the operating temperature constant. Therefore, the thermal influence of the resistive losses and $\mathrm{AC}$ losses on the critical currents is not taken into consideration.

As seen in Fig. 5, the field currents obviously exceed the critical currents in L-L-L, L-L, and L-L-Earth short circuits. A straightforward approach is to keep the field currents lower than the critical currents by operating superconducting windings with a lower load factor, i.e., giving enough safety margin. However, it is not economically satisfying to operate superconducting windings with a lower load factor. An alternatively solution could be allowing the field currents to exceed the critical currents to a reasonable extent on condition that the temperature rise is limited and superconducting windings can fully recover after short circuits are cleared [14]. This is possible if the thermal design and stabilization of the HTS coil are done in such a way that short bursts of locally dissipated heat are neutralized by the thermal inertia of the system.

\section{Forces}

The tangential force exerted on the rotor that produces the torque significantly increases owing to the occurrence of short circuits, so does the force experienced by the field winding. Table II lists the peak values of both tangential forces $F_{\tau}$ and radial forces $F_{r}$ applied on the field winding during short circuits. The reason for the large forces is that the main magnetic flux becomes larger due to increased field current.

As revealed in Table II, the tangential forces could be as high as ten times the rated values, and the radial forces could 

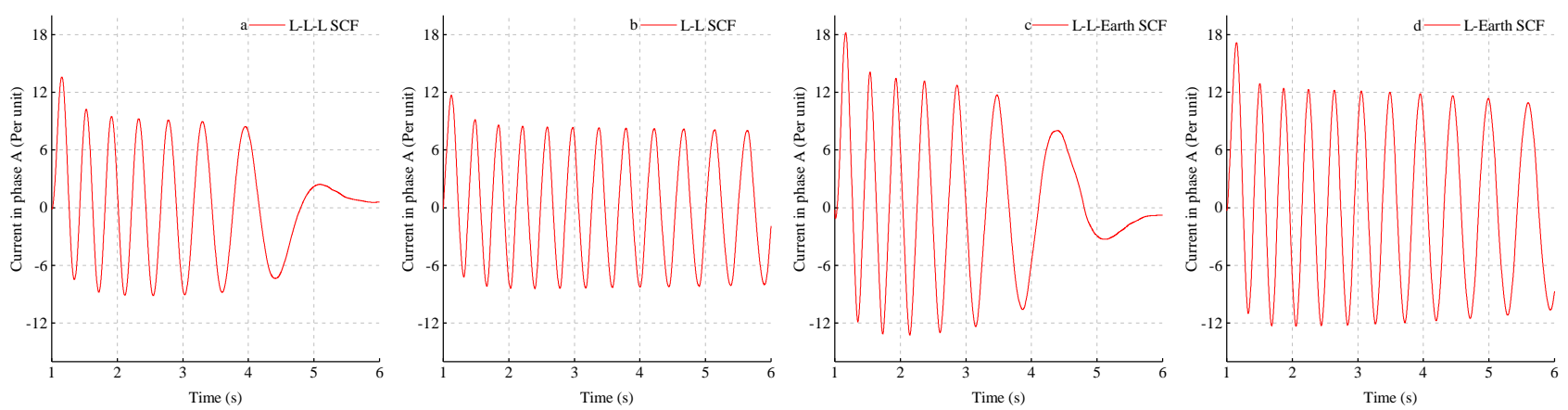

Fig. 3. Current waveforms in phase A in 5 seconds after the instant of (a) L-L-L; (b) L-L; (c) L-L-Earth; (d) L-Earth short circuit faults.
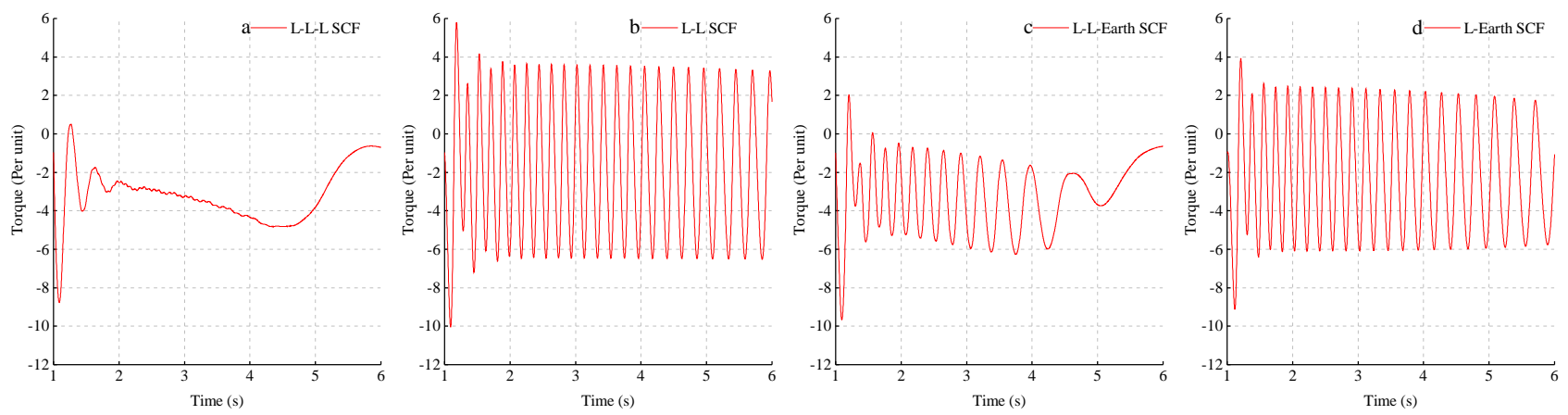

Fig. 4. Torque waveforms of the generator in 5 seconds after the instant of (a) L-L-L; (b) L-L; (c) L-L-Earth; (d) L-Earth short circuit faults.
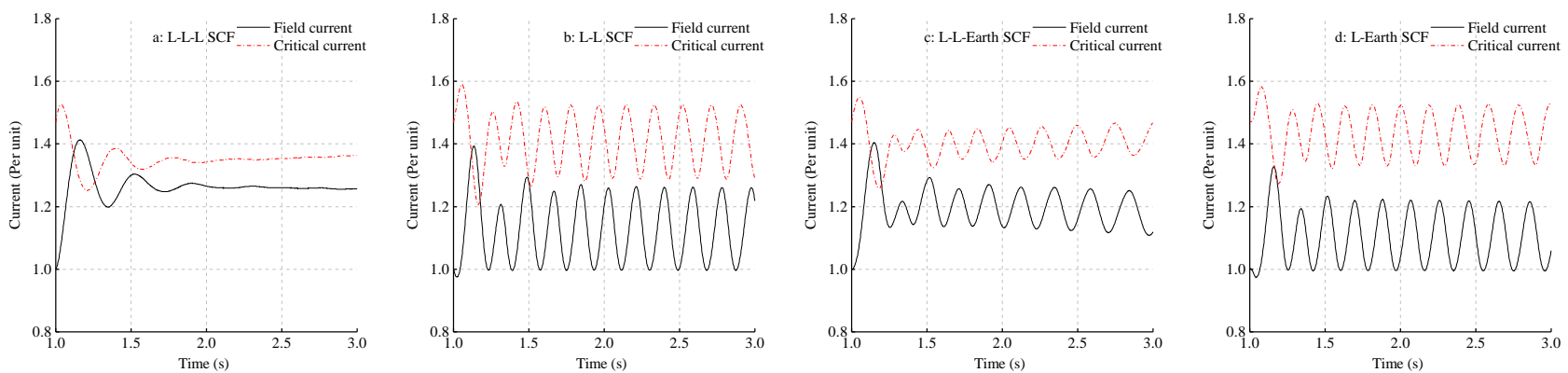

Fig. 5. Field current waveforms in 2 seconds after the instant of (a) L-L-L; (b) L-L; (c) L-L-Earth; (d) L-Earth short circuit faults. The solid lines represent the field currents while the dash lines represent the critical currents.

be four to five times the rated values. Due consideration needs to be given to these large forces since excessive stresses and strains are generated in HTS tapes, which could influence the mechanical stability of the HTS field winding. In addition, these large forces need to be handled by the supporting elements of the field winding. From an economic perspective, it is not advisable to design the supporting elements to withstand such large forces at nominal operation. A better way could be designing the supporting elements with a reasonable safety factor at nominal condition, and limiting the peak forces through a fast acting protection system, as suggested in [10].

\section{CONCLUSION}

Four types of short circuits of a 10 MW HTS wind turbine generator are systematically studied in the paper. The findings reveal that the extent of influence of short circuits on the generator depends on the types of short circuits. When rating a circuit breaker to interrupt fault currents, it is advisable to refer to a phase-phase-earth short circuit which produces a maximum fault current. A phase-phase short circuit, which results in a maximum fault torque, should be considered for the safety of the generator mechanical structure. The field currents in the HTS field winding under short circuits increase by $30 \%$ to $40 \%$, depending on the types of short circuits. The results also indicate that the field winding experiences excessive forces during short circuits, up to ten times the rated value in the tangential force and four times the rated value in the radial force.

Based on these findings, some issues need to be addressed in the future work. The over currents should be handled properly, and quantitative study of the thermal influence on the critical current is needed to avoid over heating in the field 
winding. Solutions to mitigate the consequences of different short circuits deserve in-depth study.

\section{ACKNOWLEDGEMENT}

The authors would like to thank Yuting Gao, a PhD student at the State Key Laboratory of Advanced Electromagnetic Engineering and Technology, Huazhong University of Science and Technology, China, for her troubleshooting in Ansoft Maxwell.

\section{REFERENCES}

[1] B. B. Jensen, N. Mijatovic, and A. B. Abrahamsen, "Development of superconducting wind turbine generators," J. Renew. Sustain. Energy, vol. 5, no. 2, Mar. 2013, Art. No. 023137.

[2] A. B. Abrahamsen, N. Mijatovic, E. Seiler, T. Zirngibl, C. Træholt, P. B. Nørgård, N. F. Pedersen, N. H. Andersen, and J. Østergaard, "Superconducting wind turbine generators," Supercond. Sci. Technol., vol. 23, no. 3, 2010, Art. No. 034019.

[3] G. Snitchler, B. Gamble, C. King, and P. Winn, "10 MW class superconductor wind turbine generators," IEEE Trans. Appl. Supercond., vol. 21, no. 3, pp. 1089-1092, Jun. 2011.

[4] Y. Terao, M. Sekino, and H. Ohsaki, "Comparison of conventional and superconducting generator concepts for offshore wind turbines," IEEE Trans. Appl. Supercond., vol. 23, no. 3, Jun. 2013, Art. No. 5200904.

[5] H. Karmaker, M. Ho, and D. Kulkarni, "Comparison between different design topologies for multi-megawatt direct drive wind generators using improved second generation high temperature superconductors," IEEE Trans. Appl. Supercond., vol. 25, no. 3, Jun. 2015, Art. No. 5201605.

[6] X. Song, N. Mijatovic, B. B. Jensen, and J. Holboll, "Design study of fully superconducting wind turbine generators," IEEE Trans. Appl. Supercond., vol. 25, no. 3, Jun. 2015, Art. No. 5203605.

[7] B. Seeber, Handbook of Applied Superconductivity. CRC Press, 1998, vol. 2, p. 1531.

[8] S. Umans, "Transient performance of a high-temperaturesuperconducting generator," in Electric Machines and Drives Conference, May. 2009, pp. 451-457.

[9] S. S. Kalsi, Applications of high temperature superconductors to electric power equipment. John Wiley \& Sons, 2011.

[10] R. Fair, W. Stautner, R. Rajput-Ghoshal, P. Riley, M. Moscinski, D. Wagner et al., "Superconductivity for large scale wind turbines," U.S. DOE report DE-EE0005143, Apr. 2012.

[11] G. Klaus, M. Wilke, J. Frauenhofer, W. Nick, and H.-W. Neumüller, "Design challenges and benefits of HTS synchronous machines," in Power Engineering Society General Meeting, Jun. 2007, pp. 1-8.

[12] Y. Liu, R. Qu, J. Wang, H. Fang, X. Zhang, and H. Chen, "Influences of generator parameters on fault current and torque in a large-scale superconducting wind generator," IEEE Trans. Appl. Supercond., vol. 25, no. 6, Dec. 2015, Art. ID. 5204309.

[13] D. Liu, H. Polinder, A. B. Abrahamsen, and J. A. Ferreira, "Effects of an electromagnetic shield and armature teeth on the short-circuit performance of a direct drive superconducting generator for $10 \mathrm{MW}$ wind turbines," in International Electric Machines Drives Conference (IEMDC), May. 2015, pp. 709-714.

[14] K. Sivasubramaniam, X. Huang, E. Laskaris, T. Zhang, J. Bray, J. Forgarty, and R. A. Nold, "Performance of an HTS generator field coil under system fault conditions," IEEE Trans. Appl. Supercond., vol. 16, no. 4, pp. 1971-1975, Dec. 2006.

[15] S. J. Jung, G. H. Kim, H. J. Sung, K. Kim, M. Park, I. K. Yu, K. L. Kim, H. Lee, and A. R. Kim, "Stator winding fault influence on the field coil of a $10 \mathrm{MW}$ superconducting synchronous generator," IEEE Trans. Appl. Supercond., vol. 23, no. 3, Jun. 2013, Art. ID. 5200104.

[16] E. Muljadi, N. Samaan, V. Gevorgian, J. Li, and S. Pasupulati, "Short circuit current contribution for different wind turbine generator types," in Power and Energy Society General Meeting, Jul. 2010, pp. 1-8. 